\title{
A Simplified Multiple-retrieving Small-bowel Biopsy Tube
}

\author{
Robert J. Bolt, M.D., Arthur B. French, M.D., \\ and H. Marvin Pollard, M.D.
}

\begin{abstract}
A gastrontestinal biopsy instrument depending on suction of mucosa into a capsule and separation of the mucosal fragment by a guillotine knife was first described by Wood ${ }^{1}$ in 1949 and Tomenius ${ }^{2}$ in 1950 . These tubes have proved to be both reliable and safe as a means of obtaining gastric biopsies. Unfortunately, the design of the tubes resulted in a stiffness that prevented ready passage in to the duodenum. In $1955 \mathrm{Royer}^{3}$ followed closely by Shiner, ${ }^{4}$ described the design of a more flexible tube which would pass into the duodenum and occasionally into proximal jejunum. These improvements, as well as modified versions reported by Brandborg et al., 'de Larrechea et al., ${ }^{6}$ Reichard and Westerstahl, ${ }^{7}$ and Ralston et al., ${ }^{8}$ depend on the same mechanism for obtaining biopsies. Suction is applied through a cable-like tube, and the aspirated mucosa is cut through by the guillotine-like action of a knife that is controlled by means of a pull-wire manipulated by the operator.

Although the development of these tubes acted as a potent stimulus to study of normal and abnormal small-bowel histology, their limitations soon became evident. Because a stiff tube is required to activate the knife, the instrument is not flexible enough to pass easily around the sharp angle at the ligament of Treit $\iota$. Also, it is impossible to be sure that a specimen has been obtained until the biopsy tube is removed from the patient. Finally, although more than one biopsy can sometimes be obtained, it is impossible to tell the site of origin of each specimen. The first of these limitations -lack of flexibility - has now been overcome by the development of various types of tubes eliminating the pull-wire mechanism. Three basic types have been devised. Crosby ${ }^{9}$ reported a capsule containing a knife which was "sprung loose" when sufficient suction was exerted in the capsule

From the Department of Internal Medicine (Section of Gastroenterology), Lniversity of Michigan, Ann Arbor, Mich.

Supported by Grants C3312 and A2554 from the U. S. Public Health Service.

The authors are indebted to Herbert Senecal and Edward Rupke of the University's instrument shop for manufacture of the pump and capsule.
\end{abstract}

(1) 1962 by Hofber Mfoical Division of Harpfre \& Row, Publishers, New York. 
through a small polyethylene tube; the same suction that aspirated the mucosa also resulted in release of the knife by a rubber diaphragm-spring mechanism. This capsule was easier for the patient to swallow, and biopsies could be obtained from more distal intestine.

Another type of tube was first reported by Henning et al., ${ }^{10}$ followed rapidly by Ross and Moore, ${ }^{11}$ and Obiglio and Cassina. ${ }^{12}$ In these tubes, hydrostatic pressure is substituted for the pull-wire mechanism. Another ingenious type of biopsy capsule was devised by Carey ${ }^{13}$ and reported in 1959. This is probably the simplest of all, and is operated purely by suction and air pressure. With both the hydrostatic and the air tubes, more than one specimen can be obtained, and those from more distal portions of the small bowel; in addition, positioning of the tube is easier. Unfortunately, as with previous tubes, it is impossible to know from which site the biopsies are obtained when two or more specimens are recovered. The tubes must be removed before the biopsy specimen can be retrieved, which makes it impossible to evaluate the small-bowel histologic status at given time intervals without removing and reinserting the tube.

Working independently and reporting within a year of one another, Baker and Hughes in Australia, ${ }^{14}$ Lehmann in Sweden, ${ }^{15}$ and Flick et al. ${ }^{16}$ in the United States reported on hydraulic-operated, multiple-retrieving biopsy instruments capable of obtaining an unlimited number of biopsies from anywhere in the gastrointestinal tract and of delivering them to the operator within seconds.

\section{DEVELOPMENT OF NEW BIOPSY INSTRUMENT}

We, have also, developed a multiple-retrieving biopsy instrument. It was perfected in early 1961 and has been used by us since that time without complication. During development of this tube we were unaware of the work being done by the Australian and Swedish groups, although the progress being made by Rubin's group was first brought to our attention just prior to the report made at the American Gastroenterological Association Meeting in New Orleans in May of 1960.

\section{PRESENT TUBE}

The biopsy tube which we have been using retains the desirable features of the previously mentioned tubes: (1) it is flexible because of the elimination of the pull-wire mechanism; (2) both biopsy capsule and tubing are of relatively small size; (3) any number of biopsies can be obtained from any level of the gastrointestinal tract; (4) the specimens are delivered to the operator within a matter of seconds; (5) the site from which each 
biopsy is obtained is known. Following are additional features and their accompanying advantages:

1. A coaxial system is used, so that the outside diameter of the larger tube measures only $\frac{3}{16}$ in.

2. Elimination of the Bowden spring in the capsule $(a)$ obviates special "high-pressure" pumps; $(b)$ allows use of standard, commercially available, disposable.polyethylene tubing; and $(c)$ prevents injection of water directly into the bowel lumen in the event of rupture of the inner tubing. (Water under low pressure would merely be returned to the operator via the outer tubing.)

\section{Operation}

The top clrawing ( 1 ) of Fig. 1 represents the capsule's position prior to biopsy. The glovelike object at the top represents a "knuckle" of mucosa being drawn into the capsule as the result of suction put on the outer tube in the direction represented by the heavy arrows. When the vacuum becomes steady (3-4 in.), indicating occlusion of the opening by aspirated mucosa, the pump is released and water is injected through the smaller inner tube in the direction indicated by the small arrows. We have used pump water pressures of $50-200 \mathrm{psi}$. As this pressure is transmitted to the back of the knife cylinder, the knife moves forward and cuts the mucosa, as shown in the center drawing (2) of the figure. A small aperture at the base of the knife cylinder is opened during this process, allowing the water to bypass the knife cylinder and emerge anterior to it. The biopsy specimen floats up the larger tube to the operator. The small "ball bearing" in the "bypass route" is prevented from entering the specimen chamber by a small grid with holes small enough to catch the bearing but large enough to allow the water or saline to pass unhindered. To reopen the capsule for repeated use, suction is applied to the small inner tube as depicted in the bottom diagram (3). A closed system for putting suction on the back of the knife cylinder results when the ball bearing becomes wedged at the smaller distal portion of the bypass route (3).

Figure 2 shows the parts of the capsule, illustrating the size we have found most reliable and most easily swallowed.

The actual operation of the instrument is simple, and is accomplished in the following manner (Fig. 3).

1. Desired pressure is established in the pump with lever $C$ closed. (The small, hand-operated pump used was homemade, but similar to those commercially available in Coleman* stoves.)

*Coleman Co., Inc., Wichita, Kan. 

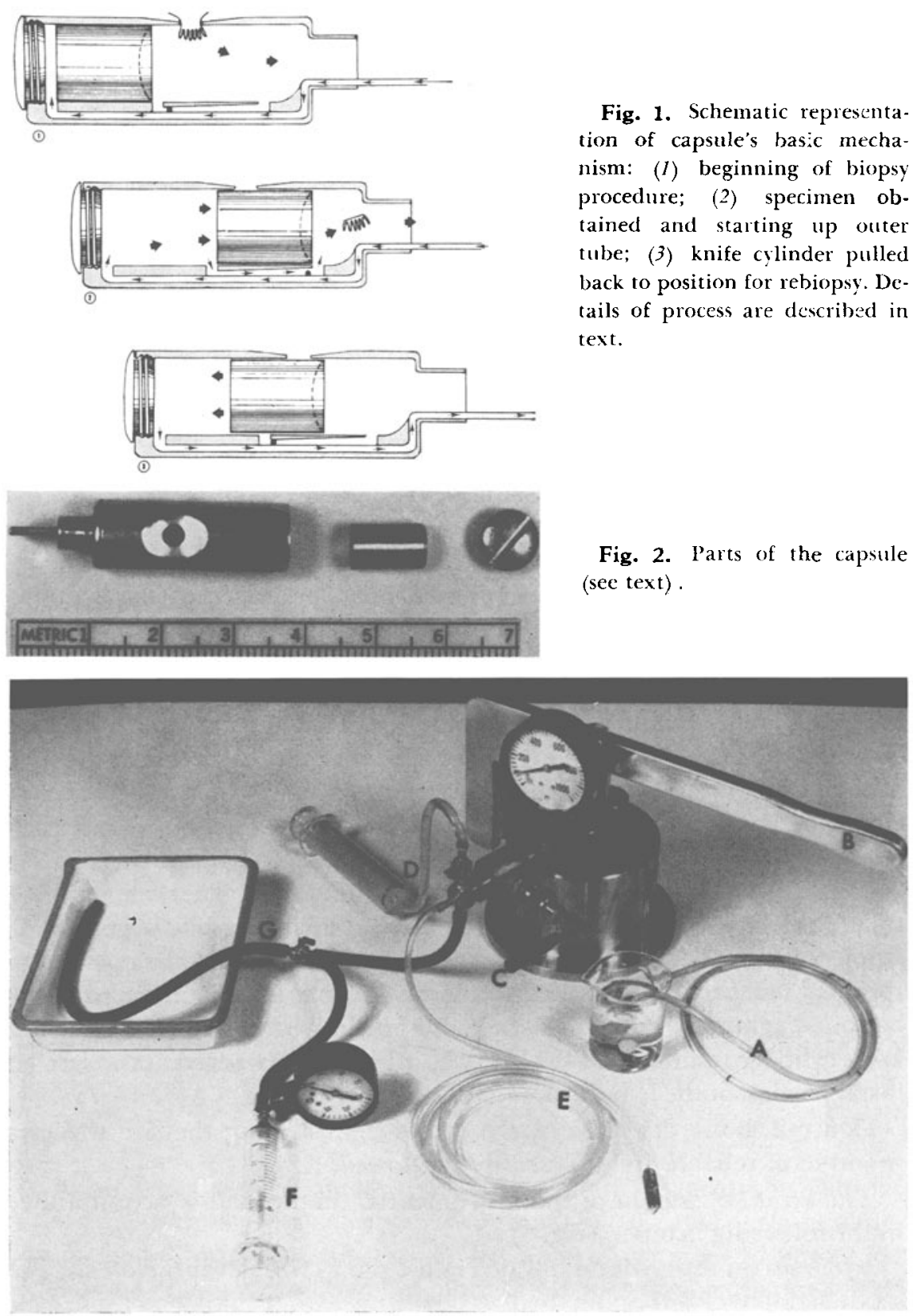

Fig. 3. The assembled biopsy capsule and pump, the parts and operation of which are described in the text.

Fig. 2. Parts of the capsule (sectext).
Fig. 1. Schematic representation of capsule's basic mechanism: (I) beginning of biopsy procedure; (2) specimen obtained and starting up outer tube; (3) knife cylinder pulled back to position for rebiopsy. Details of process are described in text. 
2. Suction with syringe $D$ assures that knife is back and aperture in capsule is open.

3. Suction with syringe $F$ pulls mucosa into aperture. When this suction holds steady (2-4 in.), the suction on syringe $D$ is released at the same time that lever $C$ is opened-shooting water down inner tube, closing knife, and washing the specimen up the outer tube and through connection tube $G$ into the receiving pan.

In Fig. 3, $A$ shows the tubing to the water source, $B$ the handle for pumping pressure, $E$ the outer Tygon $\dagger$ tubing ( $1 / 8$ in. I.I)., $\frac{3}{14 i}$ in. O.D., $1 / 32$ in. wall thickness) and inner Intramedic + tubing (.034 in. I.D., .060 in. O.D.).

We have routinely taken 2 or 3 biopsies from each of 3 sites. The first and second specimens are obtained $150-200 \mathrm{~cm}$. from the incisor teeth, the third group $70-100 \mathrm{~cm}$. from the incisor teeth. Prior to the initial biopsy, contrast medium* is injected through the small inner tubing to make certain that the tube is properly positioned. We have now obtained 240 satisfactory biopsy specimens from 40 patients, with no untoward reactions or undesirable side effects.

Medical Center

Iniversity of Michigan Ann Arbor, Wich.

\section{REFERENCES}

I. Wood, I. J., Doic, R. K., Motteram, R., and Hughes, A. Gastric biopsy. Lancet $1: 18,1949$.

2. Tomfnius, J. An instrument for gastrobiopsies. Castroenterology 15:498, 1950.

3. Royer, M., Croxatto, O.. Bifmpica, L., and Balcazar Morrisox, A. J. Biopsia duodenal por aspiracion bajo control radioscopico. Prensa Méd. Argent. f2:2515, 1955.

4a. Shinfr, M. Duodenal biopsy. Lancet $1: 17,1956$.

b. SHinfr, M. Jejunal biopsy tube, Lancet 1:85, 1956.

5. Brandborg, L. L., Rurts, C. E., and QuNion, W. E. A multipurpose instrument for suction biopsy of the esophagus, stomach, small bowel, and colon. Castroenterology $37: 1,1959$.

6. De Larrechia, J., Schapika, A., Ramos Mejia, W. Lin nuevo procedimiento para la biopsia per-oral del yeyuno. Prensa Med. Argent. 46:1328, 1959.

7. REICHARD, A. V., and WrstresstahL, N. Biopsi instrument för Tunntarm. Nord. Med. $62: 1555,1959$.

8. Ralston, M., Wood, I. J., and Hughes, A. Small bowel biopsy with the suction biopsy tube. A ustral. Ann. Med. 9:103, 1960.

9. Crosby, W. H., and Kugl:R, H. W. Intraluminal biopsy of the small intestine. Am. J. Digest. Dis. 2:236, 1957.

10. Hfaning, N., Zeimer, G., and Neugebaufr, I. Ein Gerät zür Schleimhautbiopsie in tieferen Darmabschnitten. Deutsch med. Wchnschr. 84:1961, 1959.

11. Ross, J. R., and Mooks, V. A. Small intestinal biopsy capsule utilizing hydrostatic and suction principles. Castroenterology 40:113, 1961.

†U. S. Stoneware Company, Akron, Ohio.

$\ddagger$ Clay-Adams, Inc., New York, N. Y.

*Urokon sodium $70 \%$, Mallinckrodt Chemical Works, New York, N. Y. 
12. Obiglio, H., and Cassiva, I. J. Nouvelle capsule pour biopsies de l'intestin grele. Presse Med. 68:1566, 1960.

13. CAREY, J. B., JR. Transoral intestinal biopsy studies of malabsorption syndromes and regional enteritis. Univ. Minn. Med. Bull. 30:528, 1959.

14. BaKer, S. J., and Hughes, A. Multiple retrieving small intestinal biopsy tube. Lancet $I I: 686,1960$.

15. Lenmaxi, K. E. In instrument for multiple transoral biopsies of the gastrointestinal tract. Acta med. scandinav. 169:205, 1961.

16a. FLICK, A. L., QuiNton, W. E., and RubiN, C. E. A hydraulic biopsy tube for external delivery of multiple biopsies from any level of the gastrointestinal tract. Gastroenterology 38:964, 1960 (Abst.) .

b. Flick, A. L., Quinton, W. E., and Rubin, C. E. A peroral hydraulic biopsy tube for multiple sampling at any level of the gastrointestinal tract. Gastroenterology 40: 120,1961 . 